\title{
Six Sigma diplomacy - the impact of Six Sigma on national patterns of corporate culture
}

\author{
Peter Cronemyr, Magnus Eriksson and Sebastian Jakolini
}

\section{Linköping University Post Print}

\section{Tweet}

N.B.: When citing this work, cite the original article.

This is an electronic version of an article published in:

Peter Cronemyr, Magnus Eriksson and Sebastian Jakolini, Six Sigma diplomacy - the impact of Six Sigma on national patterns of corporate culture, 2014, Total Quality Management and Business Excellence, (25), 7-8, 827-841.

Total Quality Management and Business Excellence is available online at informaworldTM:

http://dx.doi.org/10.1080/14783363.2014.906108

Copyright: Taylor \& Francis (Routledge): SSH Titles

http://www.routledge.com/

Postprint available at: Linköping University Electronic Press

http://urn.kb.se/resolve?urn=urn:nbn:se:liu:diva-110296 


\title{
Six Sigma Diplomacy - The Impact of Six Sigma on National Patterns of Corporate Culture
}

\author{
Peter Cronemyr, Magnus Eriksson, and Sebastian Jakolini \\ Quality Technology and Management \\ Linköping University, Sweden
}

Corresponding author: peter.cronemyr@liu.se

\begin{abstract}
Taking cultural aspects into account, is seldom mentioned as a success factor for implementing Six Sigma. In this paper, we elaborate on the implications of implementing and applying Six Sigma in countries with different national cultures, especially countries with non-American cultures. Based on two longitudinal case studies, we show how to take cultural aspects into account when implementing Six Sigma, and also, how implementing Six Sigma influences the local national culture of the company. We argue that taking different aspects of national cultures into account when implementing Six Sigma within a global organization, will enhance understanding, cooperation and performance of the organization.
\end{abstract}

Keywords: Six Sigma, Implementation, National Culture, Corporate Culture

\section{Introduction}

The improvement methodology of Six Sigma is a mix of Japanese and American influences. Motorola took the improvement methods of Japanese companies and moulded them into an American 'hit-the-target' project management model (Chadwick, 2007). While several American companies had failed with 'Japanese' TQM initiatives, many of the companies that adopted the more American Six Sigma methodology were a huge success in the 1990s. Today Six Sigma has become an integral part of many organisations' management culture (Antony and Banuelas, 2002).

European companies tried to follow the success of the American Six Sigma implementations, but there was resistance from some companies and scholars, who preferred the 'Japanese' TQM methods already in use to the new 'American' Six Sigma approach. They felt that 'soft' customer relations were given lower priority than 'hard' business benefit results. Six Sigma was 'too American'. Eventually something called 'European Six Sigma' emerged, claiming to be 'softer' in its design (Magnusson, Kroslid and Bergman, 2003).

So what are we talking about here? Japanese, American and European cultures; Are these relevant to implementing such a well-structured improvement methodology as Six Sigma? 
From our own experience we found that the national culture seems to influence the way Six Sigma is implemented and applied. In cooperation within global companies acting in several countries, this would probably need to be considered.

The purpose of this paper is to elaborate on the implications of implementing and applying Six Sigma in countries with different national cultures, especially countries with non-American cultures.

The research questions that we investigate in the analysis of the conducted case studies are:

- How do national cultures influence implementation and application of Six Sigma?

- How could understanding of national cultures help to implement and apply Six Sigma in international cooperation within global companies?

- How do implementation and application of Six Sigma in international cooperation within global companies influence the national cultures?

We would like to put forward the following somewhat frivolous question, summarizing the three research questions:

- Could 'Six Sigma diplomacy' be used to enhance understanding and cooperation between people from different national cultures?

\section{Methodology}

The research for this paper was conducted during approximately a decade in accordance with the methodology of a 'collaborative action inquiry' (Westlander, 1998), which seeks to integrate social sciences with organisational knowledge to generate actionable scientific knowledge. It is also described by Gummesson (2000) as 'management action research'. The major part of the development work was carried out at a global gas turbine company with development and manufacturing sites all over the world, where the first author was employed during thirteen years as a Business Excellence Manager, Black Belt and eventually Master Black Belt, implementing and conducting Six Sigma in several countries. The action research was complemented by a case study, by the second and third authors (two Swedish M.Sc. students), of implementing and conducting Six Sigma at major train equipment company with a facility in China. The basic ideas for the paper were described in the author's Ph.D. thesis (Cronemyr, 2007). The case study in China was described in a M.Sc. thesis (Eriksson and Jakolini, 2013) supervised by the first author. The final conclusions of this paper have not been published in a journal before.

\section{Theory and previous research}

\section{Six Sigma}

The widespread process improvement methodology of Six Sigma was introduced by Bill Smith at Motorola in the 1980s (Chadwick, 2007) and made famous when implemented by John F. 'Jack' Welch at General Electric (GE) in the 1990s (Eckes, 2001). Based on Japanese improvement methods, Six Sigma was designed to fit an American corporate culture. Since then, Six Sigma has spread far and wide and is now used by many companies around the world. Even though Six Sigma is a very 
structured method, each company has to adapt it to adopt it as something that fits the culture of the specific company and country.

Six Sigma is in essence a structured way of solving problems in an existing process based on analysis of real process data, i.e. facts (see e.g. Magnusson, Kroslid and Bergman, 2003). Motorola called the procedure MAIC, which at GE became DMAIC, for Define, Measure, Analyse, Improve and Control; for the phases of the Six Sigma process. One could argue that DMAIC is nothing new but a set of long well known tools but, what makes DMAIC into something new is rather the structuring of the individual tools to the process itself - basically a PDSA cycle (Plan, Do, Study, Act) put into the context of a project management model. The DMAIC process may also be regarded as a short version of the Quality Story which was developed in Japan in the 1960s (Dahlgaard et al., 1998; Dahlgaard and Dahlgaard-Park, 2006).

Six Sigma is often referred to as a 'statistical method', because decisions are made on the basis of statistical analysis of quantitative data. That is only one part of the truth. Another part that should not be forgotten - especially in Six Sigma implementation and training - is that, without qualitative methods, Six Sigma does not work. To be a Black or Green Belt, i.e. a Six Sigma project leader, you must master both the quantitative and the qualitative approaches, and use a combination of these.

Originally, as developed by Motorola, the Six Sigma methodology was mainly based on statistical analysis with the aim of reducing variation in process outputs, typically to a 'process sigma' of six, corresponding to a defect level of 3.4 defects per one million opportunities. (A 'process sigma' of six corresponds to 4.5 standard deviations due to Motorola's introduction of 'the 1.5 sigma shift' for long term variation of the mean.) Still today, emphasis is put on the statistical tools when conducting DMAIC training, some of which are quite complicated to learn and use correctly. But Six Sigma has evolved and today it is also used to improve processes where there are limited amounts of data to analyse. As applied at General Electric (Eckes, 2001), and used by many other companies, this type of approach is called the 'process door' as a contrast to the traditional 'data door' approach. In the 'process door', even though quantitative data may be limited, there are often qualitative facts to analyse; but once the root causes have been found, they still need to be verified quantitatively by some experiment or investigation.

At the beginning companies were primarily using DMAIC to improve their manufacturing process. Still today, some people associate the word 'process' directly with manufacturing. Since then the usage has spread to all types of business processes and today many see Six Sigma as something much more comprehensive than just an improvement methodology. In some companies it has become a business strategy of top management (Antony and Banuelas, 2002).

\section{Implementing Six Sigma}

The success factors in the introduction and implementation of a Six Sigma program in a company have been investigated by several authors. In a literature review Schön (2006) found success factors, suggested by Henderson and Evans (2000), Goldstein (2001), Pande et. al. (2000), Antony and Banuelas (2002) and Sandholm and Sörqvist (2002). Schön compared the suggested success factors and found extensive overlap. Fourteen success factors were selected. Furthermore, the importance of the fourteen suggested success factors was ranked in a study on how Six Sigma had been implemented in three major Swedish companies: Volvo Cars, Ericsson and SKF. 
Schön's ranking was based on how frequently the success factors were mentioned by the respondents at the companies.

The six success factors that were found to be most important were (Schön, 2006):

- Management commitment

- Focus on Training

- Project selection

- Strategy for implementation

- Linking Six Sigma to business strategy

- Focus on results

In their book "Leading Six Sigma" Snee and Hoerl (2002) compare very successful and less successful case studies of Six Sigma implementations and identify the following attributes as characteristics of the successful companies:

- Committed leadership

- Use of top talent

- Supporting infrastructure

As a contrast, the less successful companies had only 'supportive' leadership that did not really believe in Six Sigma; whoever was available was appointed Black Belt; and there was no supportive infrastructure, i.e. no formal project selection process, no formal project review process, only part time resources, and no integration with the companies' financial systems (Snee and Hoerl, 2002, p. 43).

In our own research we found the following success factors for implementing Six Sigma at a major gas turbine company (Cronemyr, 2007) which corresponds very well to what have been given in the literature:

- Management commitment

- Supporting infrastructure

- Adaptation to local organisations' situation and needs

- Project selection and methodology selection

- Use of talented full-time resources

There are no controversies about this. Most of above mentioned authors seem to agree that without these conditions you will not succeed with a Six Sigma implementation.

In addition, the following success factors for implementing Six Sigma were also identified in the gas turbine company case study, but here it is unclear whether the literature suggests these success factors. They have been mentioned, but only sporadically:

- Committed driver (mentioned by Magnusson et. al. (2003))

- Learn from history (mentioned by Schön (2006))

- Coaching (mentioned by Snee and Hoerl (2002))

- Middle management involvement (mentioned by Schön (2006))

- Take psychological aspects into account (mentioned by Antony and Banuelas (2002))

- Take cultural aspects into account (mentioned by Sandholm and Sörqvist (2002) and Schön (2006))

Here, for the first time in the lists of success factors, the word cultural appears. What do we mean by culture? 


\section{National patterns of corporate culture}

To understand the concept of culture you first have to leave your own culture and experience someone else's. When still in the culture you were raised and work, you will not take notice what behaviour is culturally determined and what is not. Trompenaars and Hampden-Turner (1997) state "Culture is like gravity: you do not experience it until you jump six feet into the air.", or in other words; culture is not something you think of until you leave your own.

The first thing you notice when coming in contact with a new culture is not a set of values or the rich history, it is the basics like food, clothing and language. That is because culture exists in different layers illustrated in Figure 1. The outer layer consists of explicit culture that is observable; food, fashion or art for instance and even specific gestures. Norms and values, the second layer, defines "right and wrong" (from norms) along with "good and bad" (from values). Norms can be laws or an understanding within a social group and can be manifested in a feeling of how one should behave (Lenkeit, 2013). Values can be seen as targets for how to behave. The norms must reflect the values or it is likely that there will be tension and instability in the society (Trompenaars and Hampden-Turner, 1997).

The core in our culture can be described by people's basic assumptions. A good way to test if something is a basic assumption is to ask "Why?" and observe the reaction. If the person gets annoyed or confused a basic assumption has probably been found. The reason for this reaction is simply that the answer to him or her is so obvious that no one should even ask the question.

The layers (Figure 1) describe the order in with a culture is experienced; outside-in, from explicit to implicit.

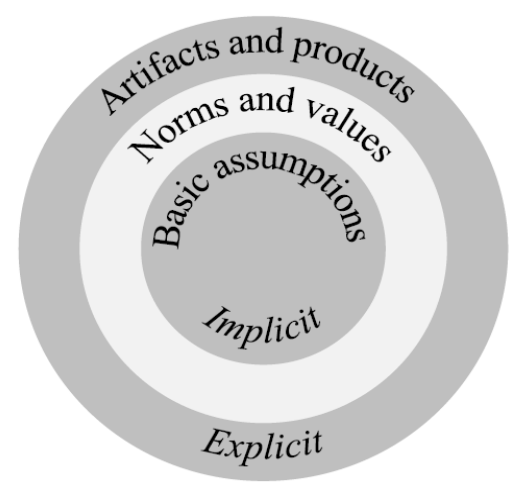

Figure 1 - Cultural layers (Trompenaars and Hampden-Turner, 1997)

Trompenaars uses a two-dimensional model (Figure 2) to describe national patterns of corporate culture (Trompenaars and Hampden-Turner, 1997). The model uses two scales - 'status' from egalitarian to hierarchical and 'orientation' from personoriented to task-oriented - to separate four different archetypes of corporate culture. These are (counter clockwise from lower left):

- Power-oriented culture - 'Family'

Description: Family relations with an experienced 'father'. Work for the good of the group. Individuals are important parts of the family.

Examples: Japan, China, India, Spain. 
- Role-oriented culture - 'Eiffel tower'

Description: Centralised collective effectiveness with a focus on reaching the goals of the business unit. Individuals should not be singled out.

Examples: Germany, Netherlands.

- Project-oriented culture - 'Guided missile'

Description: Everything is aimed at achieving a strategic target, conducted in small project teams with less top management control. Celebrate individuals' achievements related to the common goal.

Examples: USA, UK.

- Fulfilment-oriented culture - 'Incubator'

Description: The organisation should serve as an incubator for the individuals' self-fulfilment with minimal hierarchy. As individuals grow, so does the organisation.

Examples: Sweden, Norway, Canada.

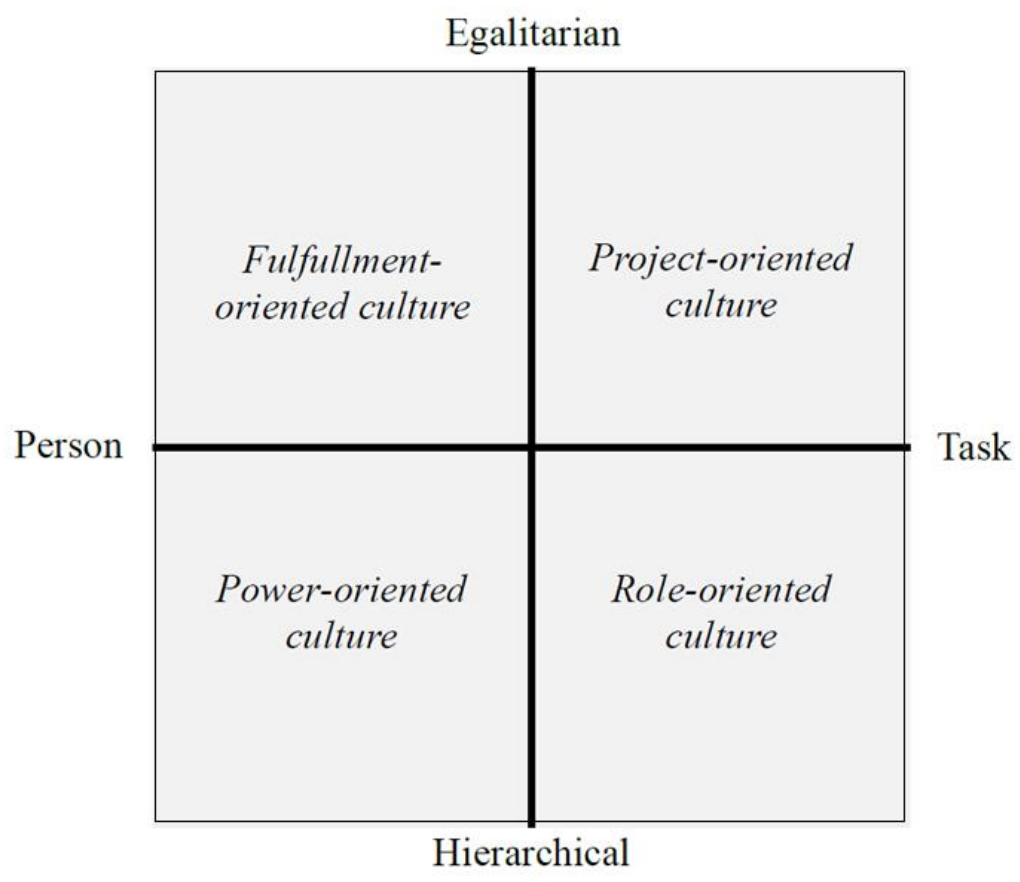

Figure 2. National patterns of corporate culture (Trompenaars and Hampden-Turner, 1997)

Hofstede (1980) uses other dimensions of culture; power distance and individualism. He writes about the power relationships between manager and employee where he explains that in some countries (including China) some employees believe in their superior's decision making solely upon that superior's position of power. Successful work in a Chinese business environment will mostly depend on the willingness for a westerner to accept a different role of authority, and the other way around for Chinese people. In China it is more important to feel that you belong and contribute to something (a group) rather than achieving personal gain and even sometimes neglect individual career opportunities if it somehow impacts the group in a negative way. In western countries the individualism is high and a person's role in the group is not seen 
as an extension of the group but instead a part of something, such as the company and the role in the company. (Triandis, Brislin and Hui, 1988).

Face in the metaphorical sense is a universal phenomenon existing in all cultures. In terms of communication the importance of face describes the degree of indirectness of communication between people. In cultures like China face plays an important role where communication between people is different depending on the level of trust and if the information exchange is in-group or out-group. Since social status and prestige are major sources of face in China, enhancing and saving face are as important as causing people to lose face. For a Westerner this can sometimes be a problem in terms of communication where the communication is direct without any intention of hurting the person receiving it (losing face). For a Chinese it is the opposite, the information shared is indirect and carefully communicated so it would not lose someone's face. (Bond and Lee, 1981; Eriksson and Jakolini, 2013).

\section{Implementing Six Sigma in a non-American culture}

Implementing Six Sigma is an endeavour of change. Some (but not several) authors have stressed the importance of taking the culture and context of the company into account instead of recommending silver bullets that could be used anywhere.

Klefsjö, Bergquist and Garvare, (2007) think that the difficulties of implementing methods within Quality Management have been dealt with in too sketchy a manner by many of its proponents. They argue that it is not certain that Six Sigma, with its American background, could seamlessly suit organisations in other parts of the world, or even suit the culture of a neighbouring firm in similar branches.

Steve Crom (2000) elaborates on the cultural aspects of implementing Six Sigma and concludes: "Six Sigma is universally applicable, though how one communicates the purpose of it and implements it should differ depending on the predominant national culture. Companies operating in Europe should beware of implementation approaches that are based on a U.S.-style emphasis on the capability of talented, well-trained individuals to get results 'no matter what it takes.'." (Crom, 2000).

Magnusson et al. (2003) discuss the reasons why Six Sigma has not achieved the same high level of attention and deployment in Europe as in the USA. Two of the reasons - related to culture - are:

- "There is an evident mistrust and lack of interest by senior management and other stakeholders to apply yet another improvement strategy of US origin", and

- "There are some implementation aspects of Six Sigma that work well in the US but may be at odds with the European cultures and management styles." (Magnusson et. al., 2003, p.28).

To sum up, one should be conscious that Six Sigma is American in its design and that it may not always fit in companies with other cultures without some adjustments.

\section{Case studies of implementing and using Six Sigma}

In this paper we analyse the results from two major case studies of implementing and using Six Sigma. One important aspect of studying cultural differences is not to judge or rank cultures as better or worse in any sense, but only to describe differences. As mentioned before, to describe one's own culture is difficult. Hence the findings given 
below are mainly based on differences identified from when it became apparent that there were misunderstandings or differences in opinions and values.

\section{Experiences from implementing and using Six Sigma in a major Gas Turbine Company in Sweden, Germany, UK and USA}

The major research for this paper was conducted as action research at a major gas turbine company during 2001 to 2007. The first author was employed as a manager of Business Excellence, a Black Belt and eventually a Master Black Belt (MBB) responsible for implementing and conducting Six Sigma globally. As in many global companies, the management structure was rather complex and will not be described in detail here. Simply put, the main office of the company was in Germany but the division under observation was managed from Sweden, so the home base was located in Sweden with company (i.e. division) sites in many countries. The most active sites were located in Sweden, Germany, UK and USA. Other locations were UAE, Russia and Netherlands.

In the beginning Six Sigma projects were mainly conducted on a local level in one country. Even so, they were followed up on a global level, so-called Six Sigma management. After some years Six Sigma projects were also conducted across the business, involving several countries.

On one occasion in a web based Six Sigma management conference the first author presented Trompenaars' model to the colleagues in Germany, USA and UK and said "now do you understand why we don't understand one another?". As one could expect, presenting a scientific paper did not give an immediate response, but there was an awareness of the differences based on some earlier experiences. Some of them are given below.

The Americans had been using Six Sigma somewhat longer than the colleagues in the other countries, who in turn had been trained by American Six Sigma training consultants. So, there should not be any real differences, but there were.

In USA, UK and in Germany there was much focus on 'hard savings', while in Sweden (at least in the beginning) most projects focused on 'soft savings'. Swedish projects were often focusing on improving customer satisfaction or employee satisfaction or improving the relations to sub suppliers. Swedish management considered these projects to be 'strategically important' but they were very difficult to translate into business benefit on the bottom-line results. When the Swedes were 'forced' into estimating the business benefit from these projects, the numbers were sometimes zero and sometimes very high, based on loose assumptions. The colleagues from USA, UK and Germany were not impressed. Furthermore, when a project resulted in reduced number of man-hours needed for a certain process or task, it was requested in Germany, UK and USA that the reduction was turned into 'real' reduction of labour-costs, otherwise the reduced time was only turned into 'more coffee breaks' (which they thought Swedes had enough of already). As a contrast, in Sweden the reduced time needed did not lead to lay-offs but instead 'time to do more and better' but that was not as easily translated into hard savings. A clear difference between Sweden on the one side and Germany/USA/UK on the other side. Later, Swedish projects were focusing more on hard savings while German, British and American projects accepted soft savings.

Another clear difference was between Germany on the one hand and USA/UK/Sweden on the other. This time it was about the scope of the projects. Sometimes Six Sigma projects has a tendency to have a very narrow focus, while in 
its original scope, a complete cross-organisational process should be analysed and improved from a customer's point of view. German projects often optimized the output from a certain department, instead of a broader process involving many departments. This was brought into attention from Swedes but German managers considered their department to be 'their process' and the German employees seldom argued with their managers. After some time though, German projects were getting broader in scope, but still with many structural obstacles like e.g. "Who will get the bonus for the improvement?".

Yet another cultural difference was how to implement the roles of Six Sigma. Strangely enough, the roles in Six Sigma are very hierarchical. Strange, because USA - the origin of Six Sigma - is not considered to be very hierarchical but it is clear the roles were influenced by the hierarchical Japanese culture they were trying to copy. The roles in a Six Sigma project are, from top to bottom: MBB, Black Belt, Green Belt and Team Member; while in Six Sigma management the roles are: Champion, Sponsor, Process owner and Business Controller/Analyst. In the very egalitarian (i.e. non-hierarchical) Sweden, as one could expect, these roles were very hard to implement. Swedes are not supposed to 'be someone' leading to people feeling stupid and being ridiculed by colleagues if they were appointed as a 'Belt' of some kind. Naturally, the roles of Six Sigma were implemented without any problems in Germany. After a couple of years the roles became 'naturalized' in Sweden while the hierarchies in Germany (at least in Six Sigma projects) were somewhat flattened out.

\section{Experiences from implementing and using Six Sigma in a Train Equipment Company in China}

In 2012 the second and third authors did their M.Sc. thesis at Linköping university (supervised by the first author, now working at the university) while conducting a Six Sigma project at a Canadian company in China. The company started its business in China in 1997. The facility produces electrical motors for trains.

The general manager of the site was Swedish, some managers were German and French, while the majority of the managers and all employees were Chinese. Most employees that participated in the Six Sigma project were Chinese. The impressions of the students were that the company had a very Chinese culture, not to any great extent affected by Canadian, Swedish, German or French cultures. Of course, that was the subjective views of two Swedes.

The Chinese facility had built its quality improvement work around inspections and had no communicated strategy how to find and solve root causes. That meant that Six Sigma would be a giant leap forward. The case study showed that implementing Six Sigma in such an organisation can be a challenge but not in any way impossible.

Six Sigma was a well-known method within the Canadian company and several employees were trained in the methodology. Even so, the view on what a Six Sigma project should consist of and what it should result in varied greatly between individuals. One common opinion was that a project should be completely driven by numbers and statistics and there was no room for qualitative data. This led to lengthy discussions with the team during the project because the amount of quantitative data to analyse was very limited. A contributing factor to this issue might have been that the opinions of the blue collar workers were not valued high enough. To solve this, the students explained and gave concrete examples of the importance of getting information from the people working with and in the processes. This gave the quantitative data more credibility in the project. It certainly increased the process 
awareness among the employees who were used to think in matters of the hierarchical organisation.

Many of the misunderstandings between the students and the team had less to do with the language they communicated in (i.e. English) but more how they communicated. For example, when a team member was asked in front of the team if he could finish his task on a specific day the answer was always "Yes" but that did not mean that the task would be done by that day. It just meant that the team member did not want to lose face in front of the team when questioned. This kind of reaction was expected since Chinese people value the personal relation higher than the business itself. This created friction within the team several times, team members saying yes to everything but delivering half of what they had promised. The Swedish project leaders trusted the team members' word and planned accordingly to what they said. However, only half the work was done when it was supposed to be finished, which lead to problems, but most important was to maintain harmony within the group.

A similar issue was the role and the authority of a local manager, who participated in the team. When the Swedish students asked the manager a question in front of the other team members, they unknowingly put him in a very bad spot. They just asked questions in a rather Swedish style, "Do you know why...?" in an investigative style, trying to get to the root cause of the problem. Even though the students were quite young, they were considered older than they actually were (due to height and beard). Also, the fact that they were foreigners, gave them authority and made them appear like 'managers from corporate functions', even though they were not. All put together, when the local manager could not answer the question, he was humiliated and lost face in front of the other employees. The Swedes were naively ignorant of this until later, when they had to try to repair the damage. Even so, after a while the team, including the manager, 'loosened up' a little and found themselves more comfortable with this less hierarchical way of working.

\section{Analysis and Discussion}

We will now analyse the experiences from the case study in the light of the theories of Six Sigma and National Patterns of Corporate Culture.

\section{Interpreting the experiences based on National Patterns of Corporate Culture}

Using the experiences from the case studies, we now classify the studied countries according to Trompenaars' model of national patterns of corporate culture.

In the study,

- Sweden was person-oriented and egalitarian, hence a Fulfilment-oriented culture,

- UK and USA were task-oriented and egalitarian, hence Project-oriented cultures,

- Germany was task-oriented and hierarchical, hence a Role-oriented culture,

- China was person-oriented and hierarchical, hence a Power-oriented culture.

So, no new findings here, other than that Trompenaars' model fits very well to the experiences of the case studies, i.e. it is correct. That is of course for the over-all classifications of the national cultures. 
We would also like to see if there are any specific Six Sigma issues related to the national cultures and whether implementing and using Six Sigma has had any impact on the cultures of the companies in the different countries.

\section{Extending the model for Six Sigma}

Trompenaars' model does not mention Six Sigma, it is more general in scope. In the applications of Six Sigma we saw that task-oriented cultures (Germany, USA and UK) were more focused on internal business benefit, what we call 'hard savings', while the person-oriented cultures (Sweden and China) focused more on maintaining and improving relations; what we call 'soft savings'. The original American design of Six Sigma emphasizes the savings from a project in dollars - from the business benefit estimation in the Define phase as the rationale of the project all along to the proved business benefit in the Control phase as 'hitting the target'. It is not easy to justify focusing on customer, employee and supplier relations, as long as it does not directly decrease costs or increase profits. In person-oriented cultures it is natural but in task-oriented cultures it is something that you have to accept.

We also saw a clear difference in the scope of the projects between hierarchical cultures (Germany and China) where the scope is narrow, limited to the local organisation, and the egalitarian cultures (Sweden, USA and UK) where broader processes crossing organisational boundaries were analysed.

Hence we could extend the model - for use in understanding application of Six Sigma in different cultures - to include 'hard/soft savings' on the $\mathrm{x}$-axis and 'organisational/process focus' on the y-axis. This might help Six Sigma practitioners cooperating over boundaries, to understand one and other.

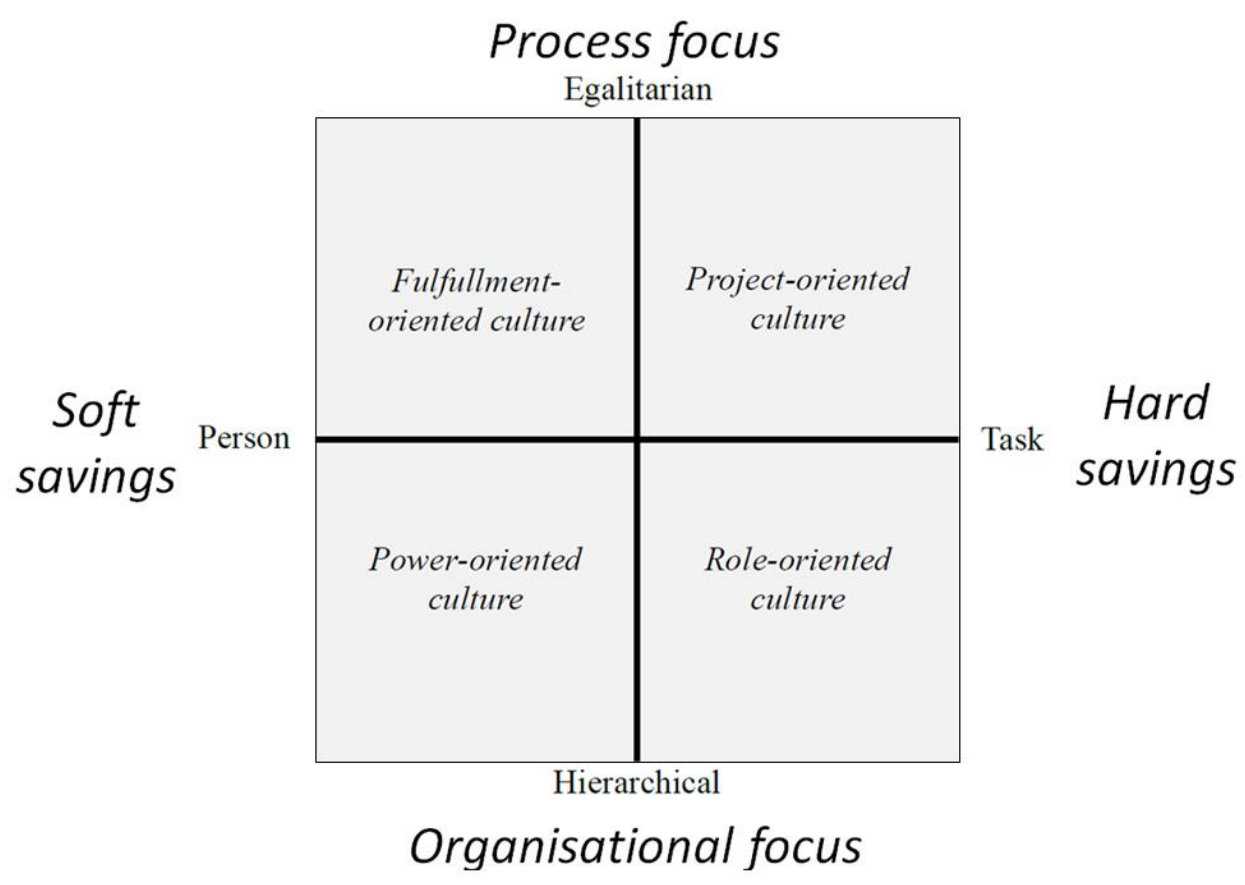

Figure 3. Focus areas of Six Sigma projects, mapped on the model for National patterns of corporate culture 


\section{The impact and evolution of TQM and Six Sigma}

As mentioned in the introduction, Six Sigma is a mix of Japanese and American influences. Improvement methods of Japanese companies were moulded into an American 'hit-the-target' project management model. Many American companies, including Motorola had tried to apply 'Japanese' TQM initiatives, but failed to 'make it work' in the American culture. It is clear that the Japanese and American corporate cultures are very different so it is not surprising. Still, TQM was a great inspiration for developing Six Sigma.

On the other hand, when Six Sigma became a success in the USA, many companies in other countries with other national cultures tried to implement Six Sigma, and that did not always work out-of-the-box. Depending on the level of difference to the American culture, Six Sigma had to be adapted to the local cultures to be adopted by the local companies. In many countries, e.g. Sweden and Germany, TQM had already been implemented more successfully than in the USA, but also with different adaptions to fit the local culture. When first implementing TQM and then Six Sigma, the results in the different countries - as we could see in the case studies - not surprisingly, looked quite different. It is necessary to realise this when trying to cooperate across cultural and national boundaries.

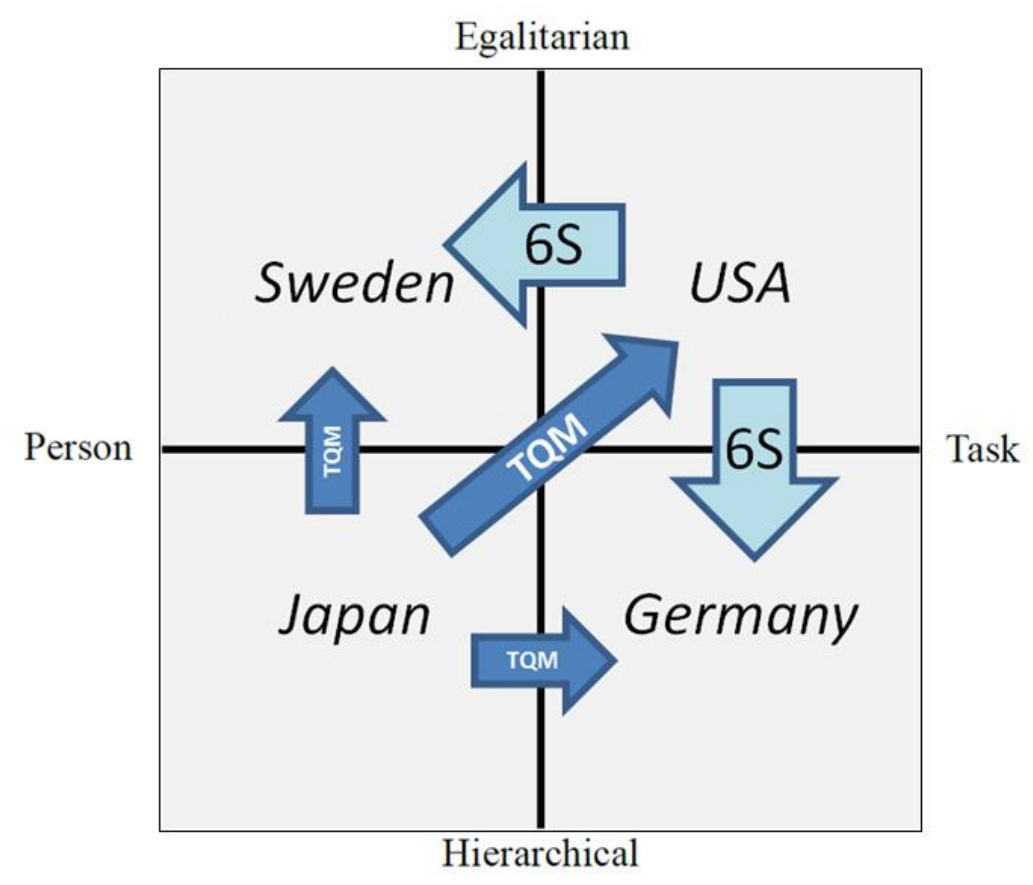

Figure 4. The impact and evolution of TQM and Six Sigma, mapped on the model for National patterns of corporate culture

\section{The impact of Six Sigma on the Culture}

We have seen that Six Sigma has to be adapted to the local culture to work. When we are talking about adaptions, it is really just minor or contextual adaptions. We have not identified any need to change the basic DMAIC cycle and the ways different tools are used. In that sense, Six Sigma is robust and well-structured. 
What we have seen though, is that implementing and using the robust and wellstructured Six Sigma, sometimes causes changes of the national culture, what we call 'cultural drift towards the middle' - meaning the middle of Trompenaars' model.

Below some examples from the case studies are given. The company(s) in...

- Sweden had to focus more on 'hard savings' which made them more taskoriented.

- Germany, USA and UK had to accept 'soft savings' which made them more person-oriented.

- Germany broadened their scope outside their department making them more process focused and somewhat more egalitarian.

- Sweden accepted the 'hierarchical' roles of Six Sigma making them more hierarchical.

- China went from inspection to Six Sigma, which was a major step in quality management, making them more task and process-oriented.

- China adapted to a less prestigious way of communicating, making them a little bit more egalitarian.

- Sweden, or rather the Swedish people in China, had to adapt the Chinese way of communicating to be more hierarchical.

So what we see is that all countries using Six Sigma in some sort of international cooperation experience a 'cultural drift towards the middle'.

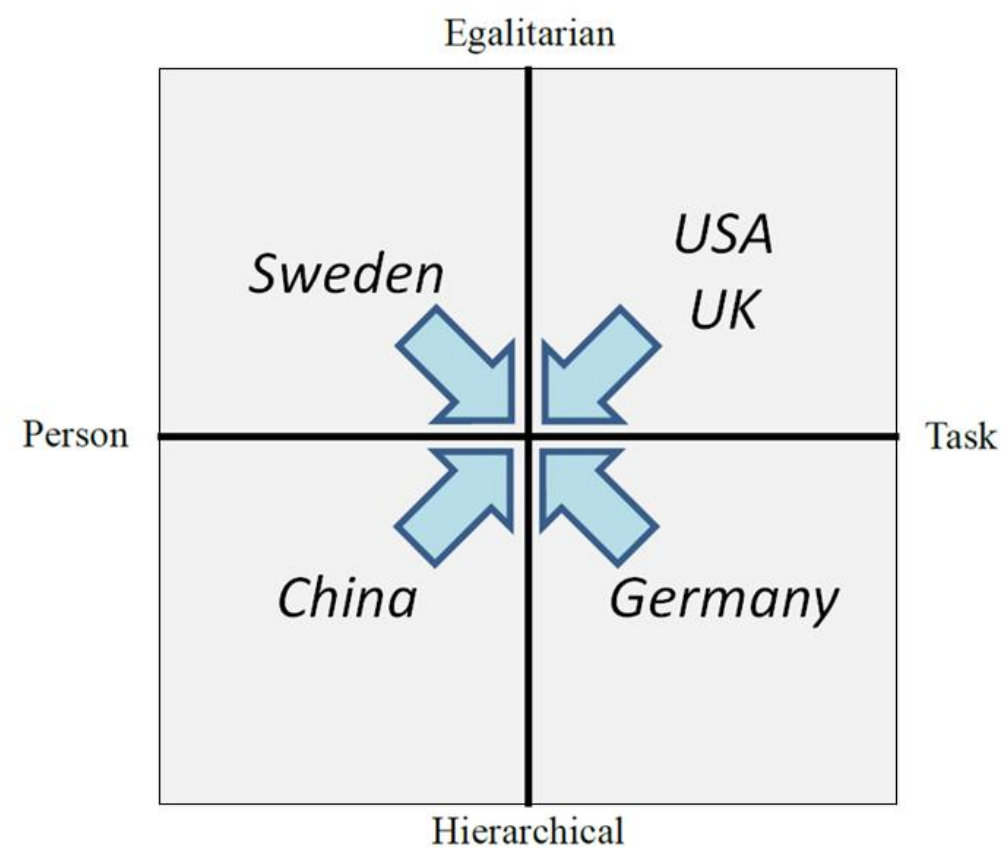

Figure 5. The impact of Six Sigma on culture, mapped on the model for National patterns of corporate culture 


\section{Conclusions and future research - Towards Six Sigma Diplomacy}

\section{Conclusions of the paper}

Revisiting the research questions of the paper we conclude the following.

How do national cultures influence implementation and application of Six Sigma?

Depending on if the culture of the company is Fulfilment-oriented, Project-oriented, Role-oriented, or Power-oriented, Six Sigma will be implemented and conducted in different ways. There will be more or less focus on hard/soft savings and organisational/process scope. We have also seen how the evolution of Six Sigma, with its roots in Japan, via the USA and spread to many other countries have been influenced along the way by the local cultures.

How could understanding of national cultures help to implement and apply Six Sigma in international cooperation within global companies?

The raising of awareness in issues concerning cultural differences between colleagues from other countries than your own has been very beneficial to the participants. As seen in the case studies, misunderstandings and differences in scope and priority have been easier to deal with.

How do implementation and application of Six Sigma in international cooperation within global companies influence the national cultures?

Six Sigma is a structured approach to quality improvement activities. This structure is a common banister for all to hold on to when using Six Sigma in international cooperation projects. In doing so, sometimes small changes of the national culture have been made. We all experience a 'cultural drift towards the middle'.

Due to this evolution, people in the participating companies now understand one another much better, and cooperate better than before. This is the consequence of cooperating in a global organisation; cultural differences languish. Six Sigma only provides the structure.

Could 'Six Sigma diplomacy' be used to enhance understanding and cooperation between people from different national cultures?

Based on the results presented in this paper we define 'Six Sigma diplomacy' as implementing and applying the structure of Six Sigma within global organisations, taking into account the different cultural aspects defined by the framework of National Patterns of Corporate Culture. With that definition, the answer to the concluding somewhat frivolous question, is yes.

\section{Research implications and future research}

Given that the major part of this research was conducted as action research, there are limitations concerning generalizability but, as generalizability is not the main purpose of action research, the outcome of the case studies were clear and helpful for the participating organisations. Given these limitations, more applications in other settings would be valuable in providing more generalizable results. 
Still, it is our opinion that this paper fills a gap in management research literature between 'general success factors for Six Sigma' and 'implementing and applying Six Sigma taking cultural context into account'.

\section{Managerial implications}

Organisations implementing Six Sigma sometimes do it without adapting it to the local culture and needs. Often, in major global organisations Six Sigma, and other initiatives with 'flavour of the day', are implemented as big standardized programmes where there is little room for adaptions. It should then be taken into account the differences in management cultures in different countries. Both to make Six Sigma work as good as possible in the local country, but especially to make international cooperation possible and effective. Cultural differences are a strength of an organisation, to be used, not a weakness to be overlooked.

\section{References}

Antony, J. and Banuelas, R. (2002) Key ingredients for the effective implementation of Six Sigma programme, Measuring Business Excellence, Vol. 6 pp. 20-27.

Bond, M. and Lee, P. (1981) Face-saving in Chinese Culture: A Discussion and Experimental Study of Hong Kong Students, in A. King and R. Lee (eds) Social Life and Development in Hong Kong, Hong Kong: Chinese University Press.

Chadwick, G. (2007) Remembering Bill Smith, Father of Six Sigma. iSixSigma Magazine, January/February: 74-76.

Crom, S. (2000) Implementing Six Sigma in Europe: a cross-cultural perspective, Quality Progress, October, pp. 73-75.

Cronemyr, P. (2007) Six Sigma Management. Ph.D. Thesis. Division of Quality Sciences, Department of Technology Management and Economics, Chalmers University of Technology.

Dahlgaard, J .J., Kristensen, K., and Kanji, G. K. (1998), Fundamentals of TQM, Carfax, London.

Dahlgaard, J. J., and Dahlgaard-Park S. M. (2006) Lean production, six sigma quality, TQM and company culture. The TQM Magazine Vol. 18 No. 3, pp. 263-281.

Eckes, G. (2001) Six Sigma Revolution: How General Electric and Others Turned Process Into Profits. John Wiley \& Sons.

Eriksson, M. and Jakolini, S. (2013) Quality Improvement and cultural differences. A case study regarding Six Sigma implementation at Bombardier Transportation in Suzhou, China. Master's Thesis, Division of Quality Technology and Management, Department of Management and Engineering, Linköping university.

Goldstein, M. D. (2001) Six Sigma programme Success Factors, Six Sigma Forum Magazine, Vol. 1, pp. 36-45.

Gummesson, E. (2000) Qualitative Methods in Management Research, $2^{\text {nd }}$ ed. Sage Publications, Newbury Park. ( $1^{\text {st }}$ ed. 1991)

Henderson, K. M. and Evans, J. R. (2000) Successful implementation of Six Sigma: benchmarking General Electric Company, Benchmarking: An International Journal, Vol. 7, pp. 260-281. 
Hofstede, G. (1980) Culture's Consequences: International Differences in Workrelated Values, Newbury Park, CA: Sage.

Klefsjö, B., Bergquist, B. and Garvare, R. (2007) Quality Management and Business Excellence, Customers and Stakeholders - Do we Agree on What We are Talking About, and Does it Matter? In the proceedings the 10th QMOD Conference. Lund's University, Campus Helsingborg.

Lenkeit, S. (2013) Human Resource Manager, Bombardier Transportation, cultural training seminar, 2013-04-15. Cited in Eriksson and Jakolini (2013).

Magnusson, K., Kroslid, D., and Bergman, B. (2003) Six Sigma. The Pragmatic Approach. Second edition. Studentlitteratur, Lund.

Pande, P.S., Neuman, R.P. and Cavanagh, R.R. (2000) The Six Sigma Way: How GE, Motorola and Other Top Companies are Honing their performance, New York, NY: McGraw-Hill Professional.

Sandholm, L. and Sörqvist, L. (2002) 12 Requirements For Six Sigma Success, Six Sigma Forum Magazine, Vol. 2, pp. 17-22.

Schön, K. (2006) Implementing Six Sigma in a non-American culture, Int. J. Six Sigma and Competitive Advantage, Vol. 2, No. 4, pp. 404-428.

Snee and Hoerl (2002) Leading Six Sigma: A Step-by-Step Guide Based on Experience with GE and Other Six Sigma Companies. Financial Times Prentice Hall.

Triandis, H., Brislin, R. and Hui, C. (1988) Cross-cultural training across the individualism-collectivism divide, International Journal of Intercultural Relations 12:269-89.

Trompenaars, F. and Hampden-Turner, C. (1997). Riding the waves of culture. 2nd ed. New York, NY: McGraw-Hill Professional.

Westlander, G. (1998) Aktionsforskning (in Swedish; English translation: Action research). Research report, Royal Institute of Technology. Stockholm. 